\title{
Early-phase administration of human amnion- derived stem cells ameliorates neurobehavioral deficits of intracerebral hemorrhage by suppressing local inflammation and apoptosis
}

\section{Yoji Kuramoto}

Hyogo College of Medicine: Hyogo Ika Daigaku

Mitsugu Fujita

Kinki University: Kinki Daigaku

\section{Toshinori Takagi}

Hyogo College of Medicine: Hyogo Ika Daigaku

\section{Yuki Takeda}

Hyogo College of Medicine: Hyogo Ika Daigaku

\section{Nobutaka Doe}

Hyogo University of Health Sciences: Hyogo Iryo Daigaku

\section{Kenichi Yamahara}

Hyogo College of Medicine: Hyogo Ika Daigaku

Shinichi Yoshimura ( $\nabla$ hyogoneuro@yahoo.co.jp)

Hyogo College of Medicine https://orcid.org/0000-0001-5633-9132

\section{Research}

Keywords: human amnion-derived stem cell, intracerebral hemorrhage, macrophage, microglia, apoptosis, inflammation

Posted Date: June 17th, 2021

DOl: https://doi.org/10.21203/rs.3.rs-623459/v1

License: (c) (1) This work is licensed under a Creative Commons Attribution 4.0 International License.

Read Full License

Version of Record: A version of this preprint was published at Journal of Neuroinflammation on February 12th, 2022. See the published version at https://doi.org/10.1186/s12974-022-02411-3. 


\section{Abstract \\ Background}

Intracerebral hemorrhage (ICH) is a significant cause of death and disabilities. Recently, cell therapies using mesenchymal stem cells have been shown to improve ICH-induced neurobehavioral deficits. Based on these findings, we designed this study to evaluate the therapeutic efficacy and underlying mechanisms by which human amnion-derived stem cells (hAMSCs) would ameliorate neurobehavioral deficits of $\mathrm{ICH}$-bearing hosts.

\section{Methods}

hAMSCs were induced from amnia obtained by cesarean section and administered intravenously to ICHbearing mice during the acute phase. The mice were then subject to multitask neurobehavioral tests at the subacute phase. We attempted to optimize the dosage and timing of the hAMSC administrations. In parallel with the hAMSCs, a 10-fold higher dose of hADSCs were used as an experimental control. Specimens were obtained from the ICH lesions to conduct immunostaining, flow cytometry, and Western blotting to elucidate the underlying mechanisms of the hAMSC treatment.

\section{Results}

The intravenous administration of hAMSCs to the ICH-bearing mice effectively improved their neurobehavioral deficits, particularly when the treatment was initiated at Day 1 after the ICH induction. Of note, the hAMSCs promoted clinical efficacy equivalent to or better than that of hADSCs at 1/10 the cell number. The systemically administered hAMSCs were found in the ICH lesions along with the local accumulation of macrophages. In details, the hAMSC treatment decreased the number of $C D 11 \mathrm{~b}^{+} \mathrm{CD} 45^{+}$ and $\mathrm{Ly}_{6 \mathrm{G}}{ }^{+}$cells in the ICH lesions, while splenocytes were not affected. Moreover, the hAMSC treatment decreased the number of apoptotic cells in the ICH lesions. These results were associated with suppression of the protein expression levels of macrophage-related factors iNOS and TNFa.

\section{Conclusions}

Intravenous hAMSC administration during the acute phase would improve ICH-induced neurobehavioral disorders. The underlying mechanism was suggested to be the suppression of subacute inflammation and apoptosis by suppressing macrophage cell numbers and macrophage functions (such as TNFa and iNOS). From a clinical point of view, hAMSC-based treatment may be a novel strategy for the treatment of $\mathrm{ICH}$.

\section{Background}


Intracerebral hemorrhage $(\mathrm{ICH})$ accounts for $10-20 \%$ of all strokes[1] [2]; its mortality rate after 1 month of onset is about $40 \%$ and its disability rate after 3 months of onset is about $60 \%$ [3] [4]. Although surgical interventions and acute medications are effective as life-saving care, they are less effective in improving neurobehavioral symptoms [5]. Rehabilitation has been a priority for functional recovery, but its therapeutic effectiveness is limited [6].

In recent years, various therapies using stem cells have been investigated and developed. Stem cells have various functions, including proliferation and self-renewal under certain conditions [7]. Stem cells are subcategorized into two major groups, depending on their stage of development. One is the embryonic stem cells that can be isolated from the inner cell mass of the blastocyst [7]. The another is the somatic stem cells, which originates from various adult tissues. Among the various types of somatic stem cells, mesenchymal stem cells (MSCs) exert unique biological effects such as the production of growth factors and cytokines, immunomodulation, neurogenesis, and angiogenesis [8]. Since MSCs are present in various tissues, such as bone marrow, adipose, and perinatal tissues, their application to various diseases is one of the major research targets. Bone marrow-derived stem cells (BMSCs) are representative MSCs that are widely approved for treating GVHD. Clinical trials are being conducted for various diseases including brain stroke [9]. Several animal studies have already shown that intravenous administration of MSCs improves neurobehavioral functions after ICH [10] [11].

The disadvantage of BMSCs is that they require an clinically invasive bone marrow aspiration, with $0.05 \%$ complications such as bleeding and infection associated with the procedure [12]. To solve this problem, we have previously established human adipose-derived stem cells (hADSCs) that is less invasively harvestable with comparable or superior abilities to produce cytokines to BMSCs [13]. Thereafter, Yamahara $\mathrm{K}$ et al. in our institute have established human amnion-derived stem cells (hAMSCs) that are isolated from fetal appendages that are often discarded after a cesarean section [14]. That is, hAMSC isolation do not require extra invasive procedures. In addition, hAMSCs have been found to secrete a variety of cytokines at higher levels comparable to BMSCs [15] and hADSCs [16]. Likewise, the immunomodulatory effects of hAMSCs on $T_{H} 1 / T_{H} 17$ immune responses are also comparable to those of BMSCs [17] [18]. Preclinical in vivo studies revealed no significant adverse events associated with the hAMSC administration [19] [20]. No major problems have been reported in human safety study [21]. Indeed, clinical trials of hAMSC are being conducted for GVHD and Crohn's disease [19] [22].

The above findings led us to hypothesize that intravenously administration of hAMSCs would improve the ICH-induced neurobehavioral deficits by altering local inflammation. To address this hypothesis, we induced ICH in the mouse brain, treated the mice with hAMSCs, and subjected the mice to multitask neurobehavioral tests. To clarify the underlying mechanisms of hAMSC-based treatment, we conducted immunostaining, TUNEL staining, flow cytometry, and Western blotting.

\section{Methods}

\section{Cell preparation of hAMSCs and hADSCs}


The Ethics Committee of Hyogo College of Medicine approved this study (approval numbers: 325 and 1880). The procedures of hAMSCs and hADSCs have been described previously[11, 14]. Briefly, we first obtained written informed consent from the donors; for hAMSC, pregnant women waiting for cesarean section, and for hADSCs, patients who underwent abdominal surgeries. Regarding hAMSCs, human fetal membranes were obtained by cesarean section. Amnia were detached mechanically from the chorion and digested with collagenase/dispase solution for $1 \mathrm{~h}$ at $37^{\circ} \mathrm{C}$ in a water bath shaker. The cells were filtered through a $100-\mu \mathrm{m}$ mesh filter, resuspended in a-minimal essential medium (a-MEM; Invitrogen, CA) supplemented with $10 \%$ bovine-derived platelet lysate "NeoSERA" (Japan biomedical, Japan), plated on dishes, and incubated at $37^{\circ} \mathrm{C}$ with $5 \% \mathrm{CO}_{2}$. Spindle-shaped cells formed visible colonies in 1-2 days. Regarding hADSCs, adipose tissues were obtained during abdominal surgeries, rinsed, cut, homogenized, digested with liberase. Stromal vascular fraction was obtained, the cells were stocked at $-80^{\circ} \mathrm{C}$ with STEM-CELLBANKER (Takara Bio) after the fourth passage.

\section{Mice and ICH induction}

The Institutional Animal Care Ethical Committee approved all the animal experiments of this study (Approval numbers: 17-034 and 19-048). The procedure has been described previously [23]. Briefly,7-9week-old male C57BL/6J mice were housed under photocyclic conditions for $12 \mathrm{~h}$ and fed with freely accessible water and food (CLEA Japan, Inc, Tokyo, Japan). The mice were anesthetized with 1.5-2.0\% isoflurane, and ICH was induced by injecting 0.4 units of collagenase AOF type A (Worthington) into the brains of mice located $2 \mathrm{~mm}$ to the left and $3.5 \mathrm{~mm}$ depth from the bregma.

\section{Administration of hAMSC or hADSC to ICH-bearing mice}

We conducted 2 experiments to optimize the dosage and timing of the hAMSC administrations. To optimize the dosage of hAMSCs and compare them with the previously studied hADSCs, mice were randomly divided into 5 groups as follows: the high-dose hAMSC group $(n=24)$, the low-dose hAMSC group $(n=11)$, the hADSC group $(n=11)$, the untreated ICH group $(n=32)$, and sham control group $(n=$ 32). Here, the high-dose hAMSC group and low-dose group received intravenous injections of hAMSC at doses of $1.0 \times 10^{5}$ cells/ $50 \mu \mathrm{l}$ and $2.5 \times 10^{4}$ cells/50 $\mu$, respectively, at $24 \mathrm{~h}$ after the ICH induction. The hADSC group received an intravenous injection of hADSC at doses of $1.0 \times 10^{6}$ cells $/ 100 \mu \mathrm{l}$ at $24 \mathrm{~h}$ after the ICH induction according to previous study [11]. The untreated $\mathrm{ICH}$ group received an intravenous injection of $50 \mu \mathrm{l}$ of vehicle control. The sham group underwent a scalp incision and trepanation alone.

The second experiment was designed to optimize the timing of the hAMSC administration. Mice were randomly divided into 4 groups: the D1-hAMSC group $(n=12)$, the D3-hAMSC group $(n=12)$, the untreated ICH group $(n=11)$, and sham control group $(n=12)$. Here, the D1-hAMSC and D3-hAMSC group received injected intravenous injections of hAMSCs at doses of $1.0 \times 10^{5}$ cells $/ 50 \mu$ at 24 and $72 \mathrm{~h}$, respectively, after the $\mathrm{ICH}$ induction. The untreated $\mathrm{ICH}$ group received an intravenous injection of $50 \mu \mathrm{l}$ of vehicle control. The sham control group underwent a scalp incision and trepanation alone.

\section{Neurobehavioral tests}


The procedure has been described previously $[11,24]$. Briefly, the following neurobehavioral tests were started at Day 29 to assess the phenotypic differences in the mice. Researchers who were blinded to the experiments evaluated the results of the tests. Details of each test are described below.

\section{Open space swimming test}

The open space swimming test was conducted to evaluate their neuromuscular strength and depressionlike symptoms of the mice. A circular pool (inside diameter: $95 \mathrm{~cm}$, depth: $35 \mathrm{~cm}$ ) surrounded by a white wall (width: $130 \mathrm{~cm}$, height: $120 \mathrm{~cm}$ ) was filled with water to a depth of $20 \mathrm{~cm}$. The water was made opaque with titanium oxide to enable a video-tracking system (Be Chase ver.1.3, ISONIX) to trace the behavior of mice. The temperature of the water was maintained at $22 \pm 1^{\circ} \mathrm{C}$. In each test, a mouse was placed in the pool with its head facing the outer edge of the pool and allowed to swim freely for $10 \mathrm{~min}$. All tests were recorded with an overhead CCD camera. The total swimming length of the subjected mouse was calculated using the video-tracking system.

\section{Morris water maze learning test}

The Morris water maze learning test was conducted to evaluate the spatial recognition of the mice. A circular pool (inside diameter: $95 \mathrm{~cm}$, depth: $35 \mathrm{~cm}$ ) surrounded by a white wall (width: $150 \mathrm{~cm}$, height: $120 \mathrm{~cm}$ ) was filled with water to a depth of $22 \mathrm{~cm}$. The water was made opaque with titanium oxide to enable the video-tracking system to trace the behavior of mice. The temperature of the water was maintained at $24 \pm 1^{\circ} \mathrm{C}$. The pool was divided into four virtual quadrants: north, south, east, and west. A round white platform (diameter: $10 \mathrm{~cm}$ ) was placed at the center of the north quadrant of the pool and submerged $0.5 \mathrm{~cm}$ below the surface of the water. In each test, a mouse was randomly released into the water with its head facing the edge of the pool in either the south, east, or west quadrants. The test ended when the subjected mouse reached the platform and stayed on it for $10 \mathrm{sec}$. If the mouse could not find the platform within $60 \mathrm{sec}$, it was guided to the platform by the experimenter and kept there for $10 \mathrm{sec}$. Each mouse was tested 5 times per day with 30 -sec intervals for 5 consecutive days. All tests were recorded with an overhead CCD camera. The duration between the release of the subjected mouse into the water and its arrival on the platform was measured as the escape latency using the video-tracking system.

\section{Passive avoidance learning test}

The passive avoidance learning test was conducted to evaluate the long-term memory function of the mice. An apparatus consisted of light and dark compartments with the same dimension $(15 \times 15 \times 15$ $\mathrm{cm}$ ) with a grid floor. A guillotine door separated the two compartments. In the conditioning test, a mouse was placed in the light compartment. Ten sec later, the guillotine door was opened. When the mouse moved into the dark compartment, the guillotine door was closed. Ten sec later, a scrambled electrical shock (at $120 \mathrm{~V}$ for $5 \mathrm{sec}$ ) was delivered through the grid floor. Twenty-four and $48 \mathrm{~h}$ later, a retention test was conducted without the electrical shock. The subjected mouse was placed in the light compartment and the duration to enter the dark compartment was recorded up to $180 \mathrm{sec}$. This duration (passive 
avoidance latency) reflected the memory functions of the subjected mice to electrical shocks with 24hour intervals.

\section{Immunostaining}

The procedure has been described previously [11]. Mice were divided into two groups: the hAMSC group that received an intravenous injection of $1.0 \times 10^{5}$ hAMSCs in $50 \mu \mathrm{l}$ of vehicle control at $24 \mathrm{~h}$ after the ICH induction, and the $\mathrm{ICH}$ group that received an intravenous injection of $50 \mu \mathrm{l}$ of vehicle control alone. The mice were sacrificed at Days 4 and 8 after the $\mathrm{ICH}$ inductions. The mice were perfused with normal saline and then $4 \%$ paraformaldehyde in PBS under deep anesthesia with 3-4\% isoflurane. Brain tissue were fixed for 1 day with $4 \%$ paraformaldehyde after removal and then transferred to $30 \%$ sucrose solution at $4^{\circ} \mathrm{C}$. The brain tissue was sectioned in 8- $\mu$ m thickness using a cryostat (CM1950, Leica Biosystems). The primary antibodies used in this experiment were as follows: anti-lba1 (ab178847, abcam) at 1:250 dilution and anti-human KU80 (STEM101, Takara Bio) at 1:100 dilution. The second antibodies used were as follows: Alexa 488-labeled anti-rabbit (CST) and Alexa 555-labeled anti-mouse (CST). DAB staining was conducted using DAB peroxidase substrate kit (SK-4100, Vector). The immunostaining assay was visualized using a fluorescence microscope (BZ-x710, Keyence)

\section{TUNEL staining}

The procedure has been described previously [25]. Briefly, frozen brain sections were immobilized with $3 \%$ $\mathrm{H}_{2} \mathrm{O}_{2} / 100 \mu \mathrm{l}$ methanol. Then, the sections were incubated for $1 \mathrm{~h}$ at room temperature with TUNEL reaction mixture that includes terminal deoxynucleotidyl transferase (TdT) and fluorescein-conjugated dUTP (In Situ Cell Death Detection Kit POD; Sigma-Aldrich). The sections were washed with PBS and incubated for $30 \mathrm{~min}$ at room temperature with anti-fluorescein antibodies conjugated with peroxidase. Then, peroxidase reacted by DAB peroxidase substrate KIT, and the images were visualized using a microscope (BZ-x710, Keyence).

\section{Flow cytometry}

The procedure has been described previously [11]. Briefly, mice were perfused with PBS under deep anesthesia with $3-4 \%$ isoflurane, and the brains and spleens were extracted. The brains were cut into small pieces and passed by 18-gauge and 20-gauge needles. The minced brain tissue was washed, resuspended in $25 \%$ Percoll (GE Healthcare), and centrifuged for $20 \mathrm{~min}$ at $500 \mathrm{~g}$. The supernatants were discarded. The cell pellets were resuspended in Histopaque (Sigma) and centrifuged for $20 \mathrm{~min}$ at $500 \mathrm{~g}$. Spleens were minced, filtered by 70- $\mu \mathrm{m}$ mesh filters, resuspended in Histopaque, and centrifuged for 20 min at $500 \mathrm{~g}$. For both, enriched immune cells were recovered at the Histopaque interface. The cells were corrected and incubated with the following antibodies: PerCP-Cy5.5-conjugated anti-mouse CD11b monoclonal antibody (BD Pharmingen), phycoerythrin (PE)-Cy7-conjugated anti-mouse CD 45 monoclonal antibody (BD Pharmingen), APC-conjugated anti-mouse Ly-6C monoclonal antibody (BD Phamingen), and BV421-conjugated anti-mouse Ly-6G monoclonal antibody (BD Horizon). Isotype controls were also used. The fluorescent-labeled cells were analyzed by LSRFortessaX-20 (BD Biosciences) and BD 
FACSDiva software (BD Biosciences). Analysis of flow cytometry results was conducted on FlowJo software version 10.5 (BD Bioscience).

\section{Protein isolation and Western blotting}

The procedure has been described previously [26] [27]. Briefly, mice were divided into two groups as described above: the hAMSC group and the ICH group. The mice were sacrificed with deep anesthesia with $3-4 \%$ isoflurane, and brain tissues were extracted and frozen immediately in liquid nitrogen. Proteins were isolated from intracerebral hematoma and perihematomal brain tissue using RIPA buffer (ATTO, WSE-7420) and denatured at $95^{\circ} \mathrm{C}$ for $5 \mathrm{~min}$. Next, denatured proteins were electrophoresed and transferred to PVDF membranes. Membrane blocking was conducted using EzBlock Chemi (ATTO, AE1475) at room temperature for $30 \mathrm{~min}$. The primary antibodies used in this study were as follows: inducible nitric oxide synthase: arginase 1 (CST, 93668) at 1:1000, iNOS (CST, 13120) at 1:1000, TNFa (Santa Cruz, SC-52746) at 1:1000, cleaved caspase 3 (Santa Cruz, SC-56053) at 1:200 dilution, PhosphoAkt (pAkt; CST, 4060) at 1:2000 dilution, p38 MARK (CST, 9212) at 1:1000 dilution, pNFK $\beta(C S T, 3039)$ at 1:1000 dilution, NFK $\beta$ (CST, 8242) at 1:1000 dilution, pSTAT3 [Tyr705] (CST, 9145) at 1:1000 dilution, pSTAT3 [Ser727] (CST,9134) at 1:1000 dilution, STAT3 (CST,30835) at 1:1000 dilution, pAkt XP $(C S T, 4060)$ at 1:1000 dilution, Akt (CST, 4685) at 1:1000 dilution and $\beta$-actin (Sigma, A5441) at 1:5000 dilution. The secondary antibodies used were as follows: HRP-conjugated goat anti-rabbit lgG $(\mathrm{H}+\mathrm{L})$ (Thermo Scientific, 32460) at 1:1000 dilution and HRP-conjugated goat anti-mouse lgG $(\mathrm{H}+\mathrm{L}$ ) (Thermo Scientific,32430) at 1:500 dilution. HRP luminescence was detected by Ez WestLumi plus (ATTO, WSE7120L) and Luminograph1 (ATTO, WSE-6100). The protein expression levels of the ICH group on Day 4 were used as control.

\section{Statistical analysis}

All the results were expressed as mean \pm SEM. For the statistical analysis of the neurobehavioral tests, repeated measures ANOVA was conducted for groups as the between-subject factor and repeated measures (e.g., session, trial, or time) as the within-subject factor. When ANOVA found significant effects, post-hoc comparison test was conducted using Tukey-Kramer method. For the statistical analyses of flow cytometry data and immunostaining date, we conducted the Wilcoxon test on each Days 2, 4, and 8. For the statistical analyses of western blotting, we conducted Tukey-Kramer test. Significance level was set at $P<.05$ (two-tailed). These statistical analyses were conducted on JMP version 15 (SAS Institute).

\section{Results}

Intravenous administration of hAMSCs dose-dependently improves ICH-induced neurobehavioral deficits during the subacute phase.

To evaluate the therapeutic efficacy and optimal dosage of hAMSCs for ICH, we induced ICH in the mouse brain and treated the mice with intravenous administration of various doses of hAMSCs. Based on the previous study where hAMSCs have been administered at doses of $1.0 \times 10^{6}$ and $4.0 \times 10^{6}$ cells per kg of body [19] [22], the administration doses of hAMSCs used in this study were calculated and 
determined as $2.5 \times 10^{4}$ and $1.0 \times 10^{5}$ per mouse. In contrast, hADSCs have been used to ICH-bearing mice at a dose of $1.0 \times 10^{6} \mathrm{hADSC}$ per mouse [11]. That is, we administered hAMSCs at $2.5 \times 10^{4}(1 / 40)$ and $1.0 \times 10^{5}(1 / 10)$ per mouse compared with the dose of hADSCs $\left(1.0 \times 10^{6}\right.$ per mouse). Subsequently, to evaluate neurobehavioral symptoms, the following multitasking behavioral tests were conducted during subacute phase: open space swimming test, water maze learning test, and passive avoidance learning test. The open space swimming test suggested significant effects of the group on swimming length (Fig. $\left.1 \mathrm{~B} ; F_{4,106}=9.5227, P=.0022\right)$ and swimming time $\left(F_{9,98}=46.6700, P<.0001\right)$. The Morris water maze learning test suggested significant effects of the group (Fig. $1 \mathrm{C} ; F_{4,94}=9.3334, P<.0001$ ) and the latency $\left(F_{4,91}=30.3615, P<.0001\right)$, with the findings that the high dose hAMSC group showed shorter latency than the untreated ICH group at Day $3(P=.0073)$, Day $4(P=.0048)$, and Day $5(P=.0092)$ and that the low dose hAMSC group showed shorter latency at Day $4(P=.0208)$ and Day $5(P=.0016)$. The passive avoidance learning test suggested significant effects of group (Fig. 1D; $F_{4,94}=20.8277, P$ $<.0001$ ), with the findings that the high dose hAMSC group showed longer latency than the untreated ICH group at 24 hours $(P<.0001)$ as well as 48 hours $(P<.0001)$ and that the hADSC also showed longer latency than the untreated ICH group on 48 hours $(P=.0186)$. These data suggest hAMSCs showed clinically comparable efficacy to the hADSCs at $1 / 10$ to $1 / 40$ of the cell number.

Early intravenous administration of hAMSCs might improve ICH-induced neurobehavioral deficits during the subacute phase.

Next, we aimed at optimizing the timing of hAMSC treatment. To this end, we treated with intravenously hAMSC administration of two timings (Days 1 and 3 after the ICH induction), and the ICH-bearing mice were subjected to the same multitask neurobehavioral test described above. The open space swimming test suggested significant effects of the group on swimming lengths (Fig. 2B; $F_{3,44}=3.966, P=.0138$ ) and time $\left(F_{9,36}=15.724, P<.0001\right)$, with the findings that the D1-hAMSC group swam longer than the untreated ICH group $(P=.0145)$ as well as the D3-hAMSC group $(P=.0452)$ at 4 minutes. The Morris water maze learning test suggested significant effects of the group (Fig. 2 C; $F_{3,44}=6.496, P=.0001$ ), with the findings that the D1-hAMSC group tended to have shorter latency than the untreated ICH group at Day $5(P=.0872)$. The passive avoidance-learning test suggested significant effects of the group (Fig. 2D; $\left.F_{3,44}=4.7152, P=.00061\right)$, with the findings that the D1-hAMSC and the D3-hAMSC groups tended to have longer latency than the untreated ICH group at 48 hours ( $P=.0526$ and $P=.063$, respectively). Taken together, these data suggest initiating the hAMSC treatment in Day 1 led to better therapeutic outcome compared with Day 3.

A small number of hAMSCs pass through the blood-brain barrier and interact with macrophage or microglial cell.

To clarify that hAMSCs enter the brain directly on the ICH, we attempted to visualize the presence of hAMSCs in the brain by anti-human Ku80 (STEM101) immunostaining. Here, STEM101 is an antibody that reacts specifically with nucleic molecule Ku80 in human cells but not cross-react with murine cells. 
Intravenous administration of hAMSCs accumulate STEM101-reactive cells around the vascular structure at Day 4 (Figs. 3A and 3B). This finding was not observed in the untreated ICH group (Fig. 3C). The hAMSC group showed STEM101-reactive cells at significantly higher levels than the control group $(P$ $=.0495$, Fig. 3D). In addition, double staining with Stem 101 and anti-lba1 antibody showed the coexistence of hAMSCs with macrophages in the ICH lesion (Fig. 3E and 3F). These findings suggested that hAMSCs would migrate to the ICH-lesion of the brain to interact with macrophages.

hAMSC administration decreases the number of $\mathrm{CD} 11 \mathrm{~b}{ }^{+} \mathrm{CD} 45^{+}$cells, $\mathrm{Ly} 6 \mathrm{C}+$ and $\mathrm{Ly} 6 \mathrm{G}^{+}$cells in the ICH lesions.

The above findings led us to hypothesize that the hAMSCs would improve the neurobehavioral deficits of $\mathrm{ICH}$-bearing mice by altering local inflammation. To address this hypothesis, we performed flow cytometry for $\mathrm{CD} 11 \mathrm{~b}^{+}$cells that include macrophages, microglia, and monocytes [30]. The hAMSC administration decreased total cell number at Day $8(P=.0475$, Fig. $4 \mathrm{~B})$ and $\mathrm{CD} 11 \mathrm{~b}^{+} \mathrm{CD} 45^{+}$cells at Day 4 $\left(P=.0433\right.$, Fig. 4C). We further examined the subpopulations of $\mathrm{CD} 11 \mathrm{~b}^{+} \mathrm{CD} 45^{+}$cells for their polarization. The hAMSC administration tended to decrease the number of $\mathrm{Ly} 6 \mathrm{C}^{+} \mathrm{Ly} 6 \mathrm{G}^{-}$cells at Day4 $(P=.075$, Fig. 4D) and significantly decreased the number of Ly6G ${ }^{+}$Ly6C ${ }^{-}$cells at Day $8(P=.012$, Fig. 4E) compared with the ICH group. These data suggest that the hAMSC administration would decrease the number of $\mathrm{CD} 11 \mathrm{~b}^{+} \mathrm{CD} 45^{+}$cells and both $\mathrm{Ly} 6 \mathrm{C}^{+}$and $\mathrm{Ly}_{6 \mathrm{G}}{ }^{+}$cells in the $\mathrm{ICH}$ lesion.

hAMSC administration does not affect $\mathrm{CD} 11 \mathrm{~b}{ }^{+} \mathrm{CD} 45^{+}$cells in the spleen.

To evaluate the systematic immune responses, we also analyzed splenic $\mathrm{CD} 11^{+} \mathrm{CD} 45^{+}$cells in the hAMSC group and the ICH group by flow cytometry (Fig. 5). Both the groups exhibited no differences in the total

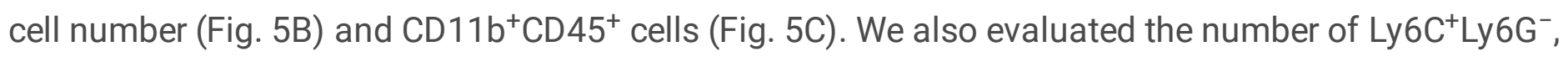

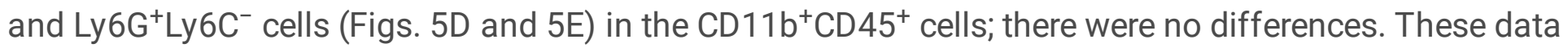
suggest that the hAMSC administration did not affect systemic immune responses and that ICH-induced inflammation was localized in the brain.

hAMSCs administration decreases the TUNEL ${ }^{+}$cells in the ICH lesions.

$\mathrm{ICH}$ has been reported to cause inflammation by macrophage and microglia, subsequently induce apoptosis of the brain [28] [29]. To evaluate the effects of hAMSCs on the ICH-indued apoptosis, we performed TUNEL staining and counted TUNEL ${ }^{+}$cells in the hAMSC and the control groups. The hAMSC groups showed TUNEL ${ }^{+}$cells on Days 4 at lower levels than the control group $(P=.0204$, Fig. 6$)$. The hAMSC administration decreased macrophage-induced apoptosis.

Intravenous administration of hAMSCs suppress protein expression of iNOS and TNFa.

ICH has been reported to affect macrophage-related factors (such as iNOS, TNFa, and arginase 1), transcriptional factors (such as NF-kB, STAT3, and p38MAPK), and apoptosis-related molecules (such as 
Caspase3) [30]. Consistent with these data, our data also demonstrated the impact of the hAMSC administration on the number of macrophages as well as apoptotic cells in the ICH lesions (Figs. 4 and 6). These findings led us to perform Western blotting to evaluate the expression levels of proteins relevant to the ICH-induced microenvironmental events. The hAMSC administration inhibited protein expression levels of TNFa at Day $4(P=.0090)$ and iNOS at Day $8(P=.00012 ;$ Fig. 7). In contrast, the hAMSC administration did not affect the expression levels of arginase 1 (Fig. 7), several transcriptional factors (p38MARK [31], NFkB [32], Akt [33], and Stat3 [34]) and apoptosis-related molecules (Caspase3 [35]; Supplement 1). These data suggest that the hAMSC administration would suppress not only the number of macrophages (Fig. 4) but their functions (iNOS and TNFa) at least partially. Taken together, our data demonstrated that the hAMSC administration ameliorated the ICH-bearing neurobehavioral deficits more effectively compared with 10-fold higher doses of hADSCs by suppressing local inflammation and apoptotic cell death in the ICH lesions.

\section{Discussion}

This study demonstrated that the hAMSC-based treatment effectively improved the neurobehavioral deficits of the $\mathrm{ICH}$-bearing mice, particularly when the treatment was initiated at Day 1 after the $\mathrm{ICH}$ induction. In the dose-comparison experiments (Fig. 1), the hAMSCs showed clinically comparable efficacy to the hADSCs at $1 / 10$ to $1 / 40$ of the cell number. In the timing-optimizing experiments (Fig. 2), initiating the hAMSC treatment in the acute phase (Day 1) led to better therapeutic outcome compared with the subacute phase (Day 3). The systemically administered hAMSCs were recruited into the ICH lesions along with the local accumulation of macrophages (Fig. 3). Detailed immunological evaluations revealed that the hAMSC treatment decreased the number of $\mathrm{CD} 11 \mathrm{~b}^{+} \mathrm{CD} 45^{+}$and $\mathrm{Ly}^{6} \mathrm{G}^{+}$cells in the ICH lesions (Fig. 4), while splenocytes were not affected (Fig. 5). The hAMSC treatment decreased the number of apoptotic cells in the ICH lesions (Fig. 6). The above results were associated with suppression of the protein expression of macrophage-related factors iNOS and TNFa (Fig. 7). Taken together, these data indicate that early initiation of hAMSC treatment, even at relatively low doses, effectively ameliorates $\mathrm{ICH}$ induced neurobehavioral deficits by suppressing local inflammation and apoptotic cell death in the ICH lesions.

When administered into the ICH-bearing mice, the hAMSCs demonstrated clinical efficacy equivalent to or better than that of hADSCs at 1/10 the cell number (Fig. 1). Until recently, the hAMSC dosage has not fully validated. In this regard, the present study demonstrated very powerful and impressive results that hAMSCs can achieve equivalent or better therapeutic efficacy with $1 / 10$ of the cell number of hADSCs. Since there has been no significant difference in the culture methods of BMSCs, hADSCs, and hAMSCs used in the previous studies [11] [14] [24] [36] [37]. This finding appears attributable to the histological origin of hAMSCs. The amniotic membrane belongs to the fetus and is flexible enough to adapt to the development of the fetus and changes in the surrounding environment (such as infections). It is highly possible that physiological hAMSCs also contribute to this property of the amnion. In fact, hAMSCs have been found to have a higher capacity to produce cytokines and less rejection than other MSCs [14] [15] 
[16] [38]. That is to say, the hAMSCs may contribute to the suppression of fetal rejection. However, most studies have only examined cultured hAMSCs and have not elucidated the physiological functions of in situ hAMSCs in amnia. This is an interesting research topic that should be investigated in the future.

The experiments to determine the timing of hAMSC administration showed better therapeutic results on Day 1 than on Day 3 after the ICH induction (Fig. 2), although the difference in the therapeutic effects was trivial. In previous studies, the common timing of MSC administration was 1 day after disease onset, as in the present study; the earliest was 1 hour and the latest was 2 months after disease onset [39]. In $\mathrm{ICH}$, microglia in the brain are activated within an hour, and a variety of inflammatory cells infiltrate the brain within a few hours [40]. The peak of these reactions has been reported to last 3-7 days, followed by several weeks $[1,30]$. Assuming that early administration of hAMSCs can decrease ICH-induced local inflammation, pre-peak administration of hAMSCs may be ideal. In this regard, our data showing better therapeutic effects of hADSC administration on Day 1 than Day 3 after the ICH induction appear reasonable.

Intravenously administered hAMSCs were found to have migrated into the brain (Fig. 3). In this regard, it remains unclear which route of administration is optimal for hAMSC treatment. There are two main routes of administration of cell therapy for intracranial lesions: intravenous and direct intracranial administration [10] [41] [42]. The advantage of intravenous administration is that it does not require any special surgical techniques or devices. This is the most realistic route when considering clinical application to humans. The disadvantage is that the administered cells are often trapped in the lungs and spleen [43], thus a larger number of cells may be required. In contrast, the advantage of direct intracranial administration is that cells can be administered near the lesion. However, the risk of local infection is unavoidable, albeit slight. In addition, and the use of stereotactic surgical systems and the development of special syringes are essential for stable and diffuse administration. Although the frequency with which intravenously administered hAMSCs reach the brain remains to be verified, the intravenous administration route appears very practical for clinical applications. Therefore, we have made it our first choice in the experimental cell therapies for CNS diseases.

The hAMSC treatment suppressed the number of macrophages and microglia in the brain (Fig. 4), which suggests that macrophages and microglia would play important roles in chronic/subacute inflammation induced by $\mathrm{ICH}$. In considering the biology of macrophages, their differentiation/polarity is of importance. Concretely, Ly6 $\mathrm{C}^{+}$macrophages are classified as M1 macrophages [44] [45] and are involved in the induction of acute inflammation [46] [47]. In contrast, Ly6G $^{+}$macrophages are classified as M2 macrophages [44] [45] and inhibit acute inflammations [48], but are also involved in chronic inflammations in asthma and COPD [49] [50] [51]. Also, the M2 macrophages have been shown to increase in the $\mathrm{ICH}$ lesions 3-7 days after onset [1]. M2 macrophages are currently classified into four major subtypes: M2a, M2b, M2c, and M2d [52]. M2a and M2c are typical anti-inflammatory subgroups and expressing Arginase 1 [53]. In contrast, M2b and M2d also express TNFa and iNOS [54]. M2 macrophages are generally associated with anti-inflammatory responses, but when overexpressed, they cause chronic inflammation. Which is consistent with our current and previous data (Fig. 7) [11]. However, 
in our model, there was no significant change in the systemic inflammatory response as shown by changes in peripheral blood and spleen (Fig. 5). Clinically, ICH is recognized as a disease that causes systemic susceptibility to infection; it is often associated with severe pneumonia and complication. There is discrepancy with the results of this study. This point needs to be re-examined in a more clinically relevant experimental system.

ICH promotes cellular damage, including cytotoxicity and oxidative stress in blood released from blood vessels as well as inflammation [55] Consistent with our data (Fig. 6), apoptosis has been observed in the $\mathrm{ICH}$ lesion [29]. In addition, a small number of hAMSCs directly reached the ICH lesions and inhibited apoptosis (Fig. 6). The main constituent cells of the brain are neurons and glial cells, while endothelial and pericyte cells exist around cerebral blood vessels. Based on the results of behavioral tests, it is highly likely that the hAMSC treatment at least suppress neuronal cell death. Furthermore, as MSCs can differentiate into all three germ layers, the hAMSCs themselves may contribute to neuronal regeneration in our experimental system. In this regard, we are currently working on a project on neural regeneration after stroke using BMSCs, hADSCs, and hAMSCs.

We performed Western blotting in this study (Fig. 7) to explain the underlying mechanisms at the protein levels of intracellular interaction and tissues. As a result, changes in iNOS and TNFa, which may contribute to the worsening of neurobehavioral symptoms, were detected in the ICH lesions followed by the hAMSC administration. However, no changes were observed in arginase-1, a representative enzyme of M2 macrophages, or in other transcriptional factors and apoptosis-related molecules, as consistent with the previous studies [56] [57] [58] [59] [60]. These data suggest that methods of evaluating tissues as a single mass, such as the one we used, is not suitable for evaluating $\mathrm{ICH}$ tissues, where changes occur in many cells. In contrast, as cell-by-cell evaluation by flow cytometry was remarkably effective in this study (Fig. 4), more detailed methods of evaluating cell-specific events such as single cell analysis would be desirable to solve these problems in the future.

\section{Conclusion}

In conclusion, the present study demonstrated that intravenous hAMSC administration during the acute phase would efficiently improve ICH-induced neurobehavioral disorders. The underlying mechanism was suggested to be the suppression of subacute inflammation and apoptosis by suppressing macrophage cell numbers and macrophage functions (such as TNFa and iNOS). From a clinical point of view, hAMSCbased treatment may be a novel strategy for the treatment of $\mathrm{ICH}$.

\section{Abbreviations}

Intracerebral hemorrhage

$\mathrm{ICH}$

Human amnion derived stem cell

hAMSC

Page $12 / 26$ 
Human adipose derived stem cell

hADSC

Bone marrow-derived stem cell

BMSC

Mesenchymal stem cell

MSC

inducible nitric oxide synthase

iNOS

Tumor-necrosis facter alpha

TNFa

\section{Declarations}

\section{Ethics approval and consent to participate}

Informed consent was obtained from all women according to our institutional ethics committee (approval number 325 and 1880).

All experiments were approved and confirmed by the Institutional Animal Care Ethical Committee (Approval number: 17-034 and 19-048).

\section{Consent for publication}

Not applicable

\section{Availability of data and material}

The datasets used and/or analyzed during the current study are available from the corresponding author on reasonable request.

\section{Competing interests}

The authors declare that they have no competing interests.

\section{Funding}

This work was supported by MEXT-Supported Program for the Strategic Research Foundation at Private Universities [Grant Number S1511034], Grant-in-Aid for Scientific Research (C) [Grant Number 19K09539],

\section{Authors' contributions}

YK drafted the manuscript, gave the final approval of the version to be published and agreed to be accountable for all aspects of the work. YT made contributions to collection data and analysis. TT, KY, ND, made substantial contributions to the analysis and interpretation of data, revised the manuscript 
critically for important intellectual content. MF and SY made substantial contributions to the study conception and design and the analysis and interpretation of data and agreed to be accountable for all aspects of the work. All authors read and approved the final manuscript.

\section{Acknowledgements}

The authors thank Makiko Murase for support of our experiments. The authors also thank the staffs in Joint-Use Research facilities, Hyogo College of Medicine for having allowed us to their resources such as flow cytometers.

\section{Availability of data and materials}

The datasets used and/or analyzed during the current study are available from the corresponding author on reasonable request.

\section{References}

1. Min $\mathrm{H}$, Jang $\mathrm{YH}$, Cho $\mathrm{I}-\mathrm{H}, \mathrm{Yu} \mathrm{S}-\mathrm{W}$, Lee SJ. Alternatively activated brain-infiltrating macrophages facilitate recovery from collagenase-induced intracerebral hemorrhage. Molecular Brain 2016, 9.

2. Shkirkova K, Schuberg S, Balouzian E, Starkman S, Eckstein M, Stratton S, Pratt FD, Hamilton S, Sharma L, Liebeskind DS, et al. Paramedic Global Impression of Change During Prehospital Evaluation and Transport for Acute Stroke. Stroke. 2020;51:784-91.

3. van Asch CJ, Luitse MJ, Rinkel GJ, van der Tweel I, Algra A, Klijn CJ. Incidence, case fatality, and functional outcome of intracerebral haemorrhage over time, according to age, sex, and ethnic origin: a systematic review and meta-analysis. Lancet Neurol. 2010;9:167-76.

4. Anderson CS, Heeley E, Huang Y, Wang J, Stapf C, Delcourt C, Lindley R, Robinson T, Lavados P, Neal $B$, et al. Rapid blood-pressure lowering in patients with acute intracerebral hemorrhage. $\mathrm{N}$ Engl J Med. 2013;368:2355-65.

5. Mendelow AD, Gregson BA, Rowan EN, Murray GD, Gholkar A, Mitchell PM. for the SIII: Early surgery versus initial conservative treatment in patients with spontaneous supratentorial lobar intracerebral haematomas (STICH II): a randomised trial. Lancet. 2013;382:397-408.

6. Saulle MF, Schambra HM. Recovery and Rehabilitation after Intracerebral Hemorrhage. Semin Neurol. 2016;36:306-12.

7. Weissman IL, Anderson DJ, Gage F. Stem and Progenitor Cells: Origins, Phenotypes, Lineage Commitments, and Transdifferentiations. Annu Rev Cell Dev Biol. 2001;17:387-403.

8. Lee HK, Finniss S, Cazacu S, Xiang C, Brodie C. Mesenchymal stem cells deliver exogenous miRNAs to neural cells and induce their differentiation and glutamate transporter expression. Stem Cells Dev. 2014;23:2851-61.

9. Hess DC, Wechsler LR, Clark WM, Savitz SI, Ford GA, Chiu D, Yavagal DR, Uchino K, Liebeskind DS, Auchus AP, et al. Safety and efficacy of multipotent adult progenitor cells in acute ischaemic stroke 
(MASTERS): a randomised, double-blind, placebo-controlled, phase 2 trial. Lancet Neurol. 2017;16:360-8.

10. Xie J, Wang B, Wang L, Dong F, Bai G, Liu Y. Intracerebral and Intravenous Transplantation Represents a Favorable Approach for Application of Human Umbilical Cord Mesenchymal Stromal Cells in Intracerebral Hemorrhage Rats. Med Sci Monit. 2016;22:3552-61.

11. Kuramoto Y, Takagi T, Tatebayashi K, Beppu M, Doe N, Fujita M, Yoshimura S. Intravenous administration of human adipose-derived stem cells ameliorates motor and cognitive function for intracerebral hemorrhage mouse model. Brain Res. 2019;1711:58-67.

12. Bain BJ. Bone marrow biopsy morbidity and mortality. Br J Haematol. 2003;121:949-51.

13. Ikegame Y, Yamashita K, Hayashi S, Mizuno H, Tawada M, You F, Yamada K, Tanaka Y, Egashira Y, Nakashima S, et al. Comparison of mesenchymal stem cells from adipose tissue and bone marrow for ischemic stroke therapy. Cytotherapy. 2011;13:675-85.

14. Yamahara K, Harada K, Ohshima M, Ishikane S, Ohnishi S, Tsuda H, Otani K, Taguchi A, Soma T, Ogawa $\mathrm{H}$, et al. Comparison of angiogenic, cytoprotective, and immunosuppressive properties of human amnion- and chorion-derived mesenchymal stem cells. PLoS One. 2014;9:e88319.

15. Raynaud CM, Maleki M, Lis R, Ahmed B, Al-Azwani I, Malek J, Safadi FF, Rafii A. Comprehensive characterization of mesenchymal stem cells from human placenta and fetal membrane and their response to osteoactivin stimulation. Stem Cells Int. 2012;2012:658356.

16. Borem R, Madeline A, Bowman M, Gill S, Tokish J, Mercuri J. Differential Effector Response of Amnion- and Adipose-Derived Mesenchymal Stem Cells to Inflammation; Implications for Intradiscal Therapy. J Orthop Res. 2019;37:2445-56.

17. Tsuda H, Yamahara K, Otani K, Okumi M, Yazawa K, Kaimori JY, Taguchi A, Kangawa K, Ikeda T, Takahara S, Isaka Y. Transplantation of allogenic fetal membrane-derived mesenchymal stem cells protects against ischemia/reperfusion-induced acute kidney injury. Cell Transplant. 2014;23:889-99.

18. Ohshima M, Yamahara K, Ishikane S, Harada K, Tsuda H, Otani K, Taguchi A, Miyazato M, Katsuragi $\mathrm{S}$, Yoshimatsu J, et al. Systemic transplantation of allogenic fetal membrane-derived mesenchymal stem cells suppresses Th1 and Th17 T cell responses in experimental autoimmune myocarditis. J Mol Cell Cardiol. 2012;53:420-8.

19. Yamahara K, Hamada A, Soma T, Okamoto R, Okada M, Yoshihara S, Yoshihara K, Ikegame K, Tamaki H, Kaida K, et al: Safety and efficacy of amnion-derived mesenchymal stem cells (AM01) in patients with steroid-refractory acute graft-versus-host disease after allogeneic haematopoietic stem cell transplantation: a study protocol for a phase I/II Japanese trial. BMJ Open 2019, 9.

20. Miyamoto S, Ohnishi S, Onishi R, Tsuchiya I, Hosono H, Katsurada T, Yamahara K, Takeda H, Sakamoto N. Therapeutic effects of human amnion-derived mesenchymal stem cell transplantation and conditioned medium enema in rats with trinitrobenzene sulfonic acid-induced colitis. Am J Transl Res. 2017;9:940-52.

21. Lim R, Malhotra A, Tan J, Chan ST, Lau S, Zhu D, Mockler JC, Wallace EM. First-In-Human Administration of Allogeneic Amnion Cells in Premature Infants With Bronchopulmonary Dysplasia: 
A Safety Study. Stem Cells Transl Med. 2018;7:628-35.

22. Otagiri S, Ohnishi S, Miura A, Hayashi H, Kumagai I, Ito YM, Katsurada T, Nakamura S, Okamoto R, Yamahara K, et al. Evaluation of amnion-derived mesenchymal stem cells for treatment-resistant moderate Crohn's disease: study protocol for a phase I/II, dual-centre, open-label, uncontrolled, doseresponse trial. BMJ Open Gastroenterol. 2018;5:e000206.

23. Krafft PR, Rolland WB, Duris K, Lekic T, Campbell A, Tang J, Zhang JH. Modeling intracerebral hemorrhage in mice: injection of autologous blood or bacterial collagenase. $J$ Vis Exp 2012:e4289.

24. Tatebayashi K, Takagi T, Fujita M, Doe N, Nakagomi T, Matsuyama T, Yoshimura S. Adipose-derived stem cell therapy inhibits the deterioration of cerebral infarction by altering macrophage kinetics. Brain Res. 2019;1712:139-50.

25. Mishiro K, Imai T, Sugitani S, Kitashoji A, Suzuki Y, Takagi T, Chen H, Oumi Y, Tsuruma K, Shimazawa $\mathrm{M}, \mathrm{Hara} \mathrm{H}$. Diabetes mellitus aggravates hemorrhagic transformation after ischemic stroke via mitochondrial defects leading to endothelial apoptosis. PLoS One. 2014;9:e103818.

26. Takagi T, Imai T, Mishiro K, Ishisaka M, Tsujimoto M, Ito H, Nagashima K, Matsukawa H, Tsuruma K, Shimazawa $\mathrm{M}$, et al. Cilostazol ameliorates collagenase-induced cerebral hemorrhage by protecting the blood-brain barrier. J Cereb Blood Flow Metab. 2017;37:123-39.

27. Yang P, Wu J, Miao L, Manaenko A, Matei N, Zhang Y, Xu L, Pearce WJ, Hartman RE, Obenaus A, et al. Platelet-Derived Growth Factor Receptor-beta Regulates Vascular Smooth Muscle Cell Phenotypic Transformation and Neuroinflammation After Intracerebral Hemorrhage in Mice. Crit Care Med. 2016;44:e390-402.

28. Matsushita K, Meng W, Wang X, Asahi M, Asahi K, Moskowitz MA, Lo EH. Evidence for apoptosis after intercerebral hemorrhage in rat striatum. J Cereb Blood Flow Metab. 2000;20:396-404.

29. Qureshi Al, Suri MFK, Ostrow PT, Kim SH, Ali Z, Shatla AA, Guterman LR, Hopkins LN. Apoptosis as a Form of Cell Death in Intracerebral Hemorrhage. Neurosurgery. 2003;52:1041-8.

30. Zhao X, Zhang Y, Strong R, Zhang J, Grotta JC, Aronowski J. Distinct patterns of intracerebral hemorrhage-induced alterations in NF-kappaB subunit, iNOS, and COX-2 expression. J Neurochem. 2007;101:652-63.

31. Cao X, Rui L, Pennington PR, Chlan-Fourney J, Jiang Z, Wei Z, Li XM, Edmondson DE, Mousseau DD. Serine 209 resides within a putative p38(MAPK) consensus motif and regulates monoamine oxidaseA activity. J Neurochem. 2009;111:101-10.

32. Sharp GC, Ma H, Saunders PT, Norman JE. A computational model of lipopolysaccharide-induced nuclear factor kappa B activation: a key signalling pathway in infection-induced preterm labour. PLoS One. 2013;8:e70180.

33. Gao X, Zhang H, Steinberg G, Zhao H. The Akt pathway is involved in rapid ischemic tolerance in focal ischemia in Rats. Transl Stroke Res. 2010;1:202-9.

34. Jung JE, Kim GS, Chan PH. Neuroprotection by interleukin-6 is mediated by signal transducer and activator of transcription 3 and antioxidative signaling in ischemic stroke. Stroke. 2011;42:3574-9. 
35. Fan W, Dai Y, Xu H, Zhu X, Cai P, Wang L, Sun C, Hu C, Zheng P, Zhao BQ. Caspase-3 modulates regenerative response after stroke. Stem Cells. 2014;32:473-86.

36. Dabrowska S, Andrzejewska A, Strzemecki D, Muraca M, Janowski M, Lukomska B. Human bone marrow mesenchymal stem cell-derived extracellular vesicles attenuate neuroinflammation evoked by focal brain injury in rats. J Neuroinflammation. 2019;16:216.

37. Seyfried D, Ding J, Han Y, Li Y, Chen J, Chopp M. Effects of intravenous administration of human bone marrow stromal cells after intracerebral hemorrhage in rats. Journal of Neurosurgery JNS. 2006;104:313-8.

38. Li Y, Liu Z, Tang Y, Feng W, Zhao C, Liao J, Zhang C, Chen H, Ren Y, Dong S, et al. Schnurri-3 regulates BMP9-induced osteogenic differentiation and angiogenesis of human amniotic mesenchymal stem cells through Runx2 and VEGF. Cell Death Dis. 2020;11:72.

39. Turnbull MT, Zubair AC, Meschia JF, Freeman WD. Mesenchymal stem cells for hemorrhagic stroke: status of preclinical and clinical research. npj Regenerative Medicine. 2019;4:10.

40. Aronowski J, Zhao X. Molecular pathophysiology of cerebral hemorrhage: secondary brain injury. Stroke. 2011;42:1781-6.

41. Chen J, Li Y, Wang L, Lu M, Zhang X, Chopp M. Therapeutic benefit of intracerebral transplantation of bone marrow stromal cells after cerebral ischemia in rats. J Neurol Sci. 2001;189:49-57.

42. Liao W, Zhong J, Yu J, Xie J, Liu Y, Du L, Yang S, Liu P, Xu J, Wang J, et al. Therapeutic benefit of human umbilical cord derived mesenchymal stromal cells in intracerebral hemorrhage rat: implications of anti-inflammation and angiogenesis. Cell Physiol Biochem. 2009;24:307-16.

43. Schrepfer S, Deuse T, Reichenspurner H, Fischbein MP, Robbins RC, Pelletier MP. Stem cell transplantation: the lung barrier. Transplant Proc. 2007;39:573-6.

44. Sica A, Mantovani A. Macrophage plasticity and polarization: in vivo veritas. J Clin Invest. 2012;122:787-95.

45. Yang J, Zhang L, Yu C, Yang X-F, Wang H. Monocyte and macrophage differentiation: circulation inflammatory monocyte as biomarker for inflammatory diseases. Biomark Res. 2014;2:1.

46. Graubardt N, Vugman M, Mouhadeb O, Caliari G, Pasmanik-Chor M, Reuveni D, Zigmond E, Brazowski E, David E, Chappell-Maor L, et al. Ly6C(hi) Monocytes and Their Macrophage Descendants Regulate Neutrophil Function and Clearance in Acetaminophen-Induced Liver Injury. Front Immunol. 2017;8:626.

47. Swirski FK, Libby P, Aikawa E, Alcaide P, Luscinskas FW, Weissleder R, Pittet MJ. Ly-6Chi monocytes dominate hypercholesterolemia-associated monocytosis and give rise to macrophages in atheromata. Journal of Clinical Investigation. 2007;117:195-205.

48. Cherry JD, Olschowka JA, O'Banion MK. Neuroinflammation and M2 microglia: the good, the bad, and the inflamed. J Neuroinflammation. 2014;11:98.

49. Nowroozilarki N, Oz HH, Schroth C, Hector A, Nurnberg B, Hartl D, Kolahian S. Anti-inflammatory role of CD11b(+)Ly6G(+) neutrophilic cells in allergic airway inflammation in mice. Immunol Lett. 2018;204:67-74. 
50. Girodet PO, Nguyen D, Mancini JD, Hundal M, Zhou X, Israel E, Cernadas M. Alternative Macrophage Activation Is Increased in Asthma. Am J Respir Cell Mol Biol. 2016;55:467-75.

51. Kaku Y, Imaoka H, Morimatsu Y, Komohara Y, Ohnishi K, Oda H, Takenaka S, Matsuoka M, Kawayama T, Takeya M, Hoshino T. Overexpression of CD163, CD204 and CD206 on alveolar macrophages in the lungs of patients with severe chronic obstructive pulmonary disease. PLoS One. 2014;9:e87400.

52. Roszer T. Understanding the Mysterious M2 Macrophage through Activation Markers and Effector Mechanisms. Mediators Inflamm. 2015;2015:816460.

53. Jetten N, Verbruggen S, Gijbels MJ, Post MJ, De Winther MP, Donners MM. Anti-inflammatory M2, but not pro-inflammatory M1 macrophages promote angiogenesis in vivo. Angiogenesis. 2014;17:10918.

54. Wang LX, Zhang SX, Wu HJ, Rong XL, Guo J. M2b macrophage polarization and its roles in diseases. J Leukoc Biol. 2019;106:345-58.

55. Gong YH, Hao SL, Wang BC. Mesenchymal Stem Cells Transplantation in Intracerebral Hemorrhage: Application and Challenges. Front Cell Neurosci. 2021;15:653367.

56. Chen M, Li X, Zhang X, He X, Lai L, Liu Y, Zhu G, Li W, Li H, Fang Q, et al. The inhibitory effect of mesenchymal stem cell on blood-brain barrier disruption following intracerebral hemorrhage in rats: contribution of TSG-6. J Neuroinflammation. 2015;12:61.

57. Feldmann M, Brennan FM, Elliott M, Katsikis P, Maini RN. TNF alpha as a therapeutic target in rheumatoid arthritis. Circ Shock. 1994;43:179-84.

58. Takada Y, Sung B, Sethi G, Chaturvedi MM, Aggarwal BB. Evidence that genetic deletion of the TNF receptor p60 or p80 inhibits Fas mediated apoptosis in macrophages. Biochem Pharmacol. 2007;74:1057-64.

59. Bernstein JE, Savla P, Dong F, Zampella B, Wiginton JGt, Miulli DE, Wacker MR, Menoni R. Inflammatory Markers and Severity of Intracerebral Hemorrhage. Cureus. 2018;10:e3529.

60. Silva Y, Leira R, Tejada J, Lainez JM, Castillo J, Davalos A. Stroke Project CDGotSNS: Molecular signatures of vascular injury are associated with early growth of intracerebral hemorrhage. Stroke. 2005;36:86-91.

\section{Figures}


A.

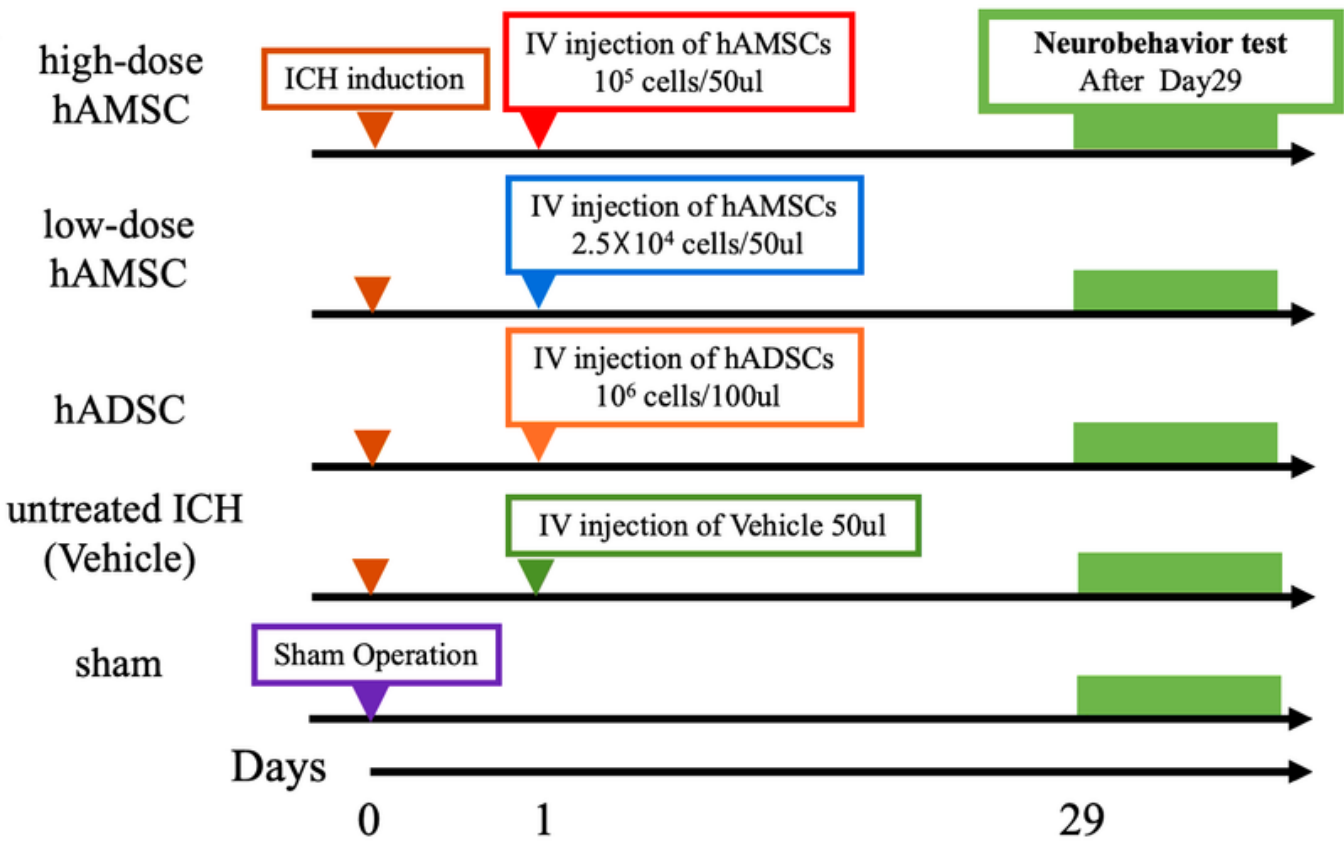

B
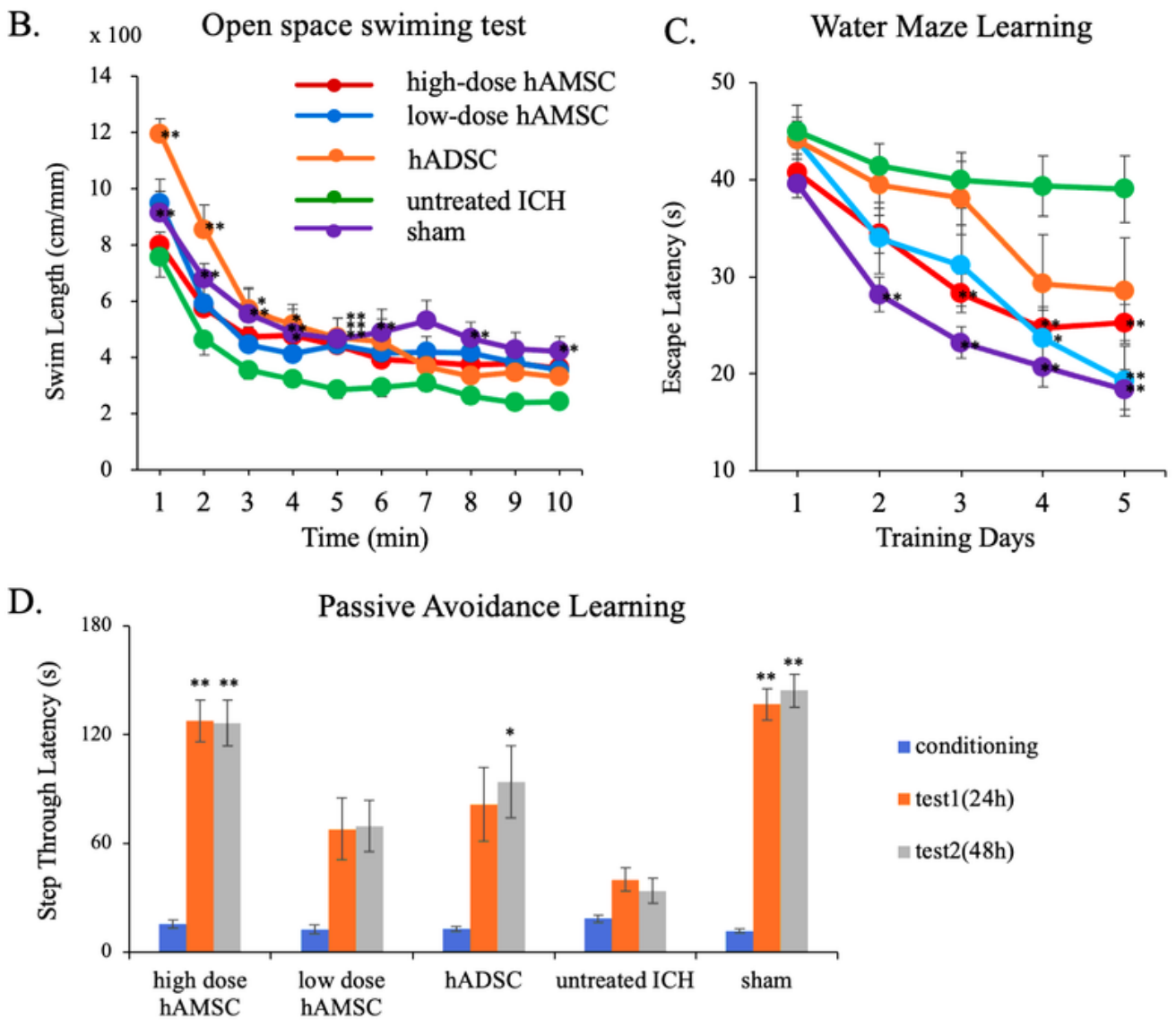

\section{Figure 1}

Intravenous administration of hAMSCs dose-dependently improves ICH-induced neurobehavioral deficits during the subacute phase. A, a protocol of neurobehavioral tests to optimize the administration dose of hAMSCs for mice bearing bearing intracranial hemorrhage $(\mathrm{ICH})$, The mice were divided into five groups: high-dose hAMSC group ( $n=24)$, low-dose hAMSC group $(n=11)$, hADSC group ( $n=11)$, ICH group ( $n=32)$, and sham group $(n=32)$. The mice were then subject to the following neurobehavioral tests at Day 29 and 
later: open space swimming test (B), water maze learning test (C), and passive avoidance learning test (D). Data are plotted in mean \pm SEM. $P$ values are based on Tukey-Kramer test. * $P<.05$ and ${ }^{\star *} P<.01$ compared with the ICH group.

A.

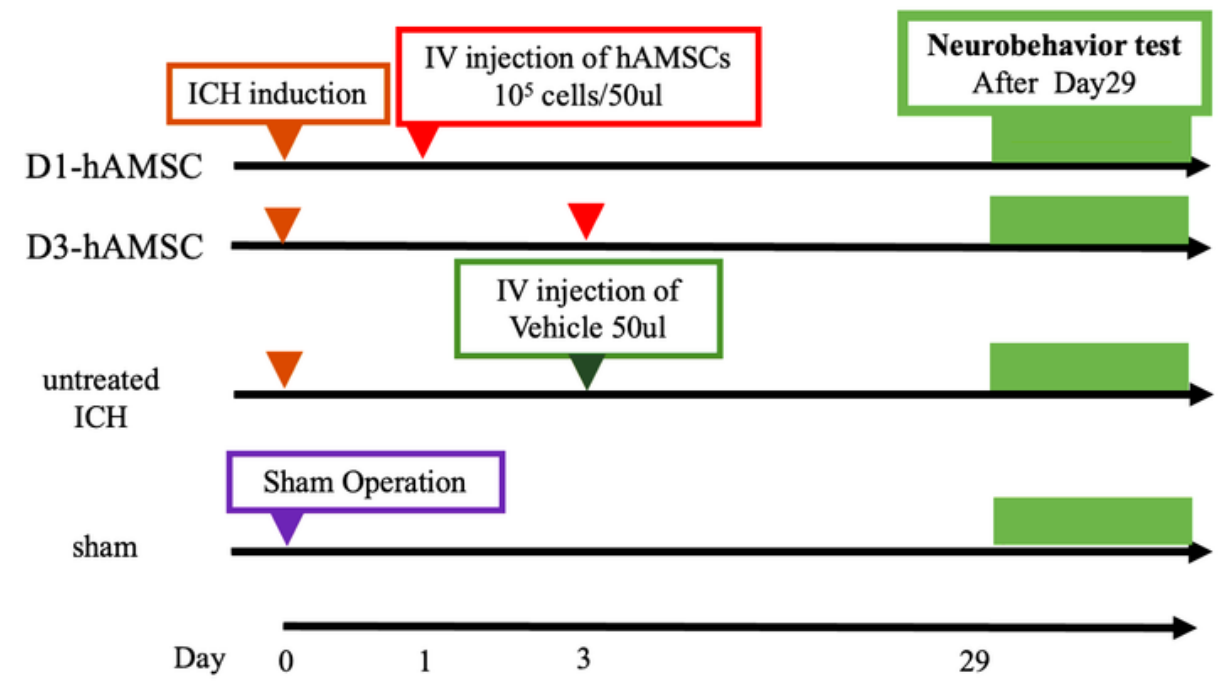

B. Open Space Swimming Test

C. Water Maze Learning
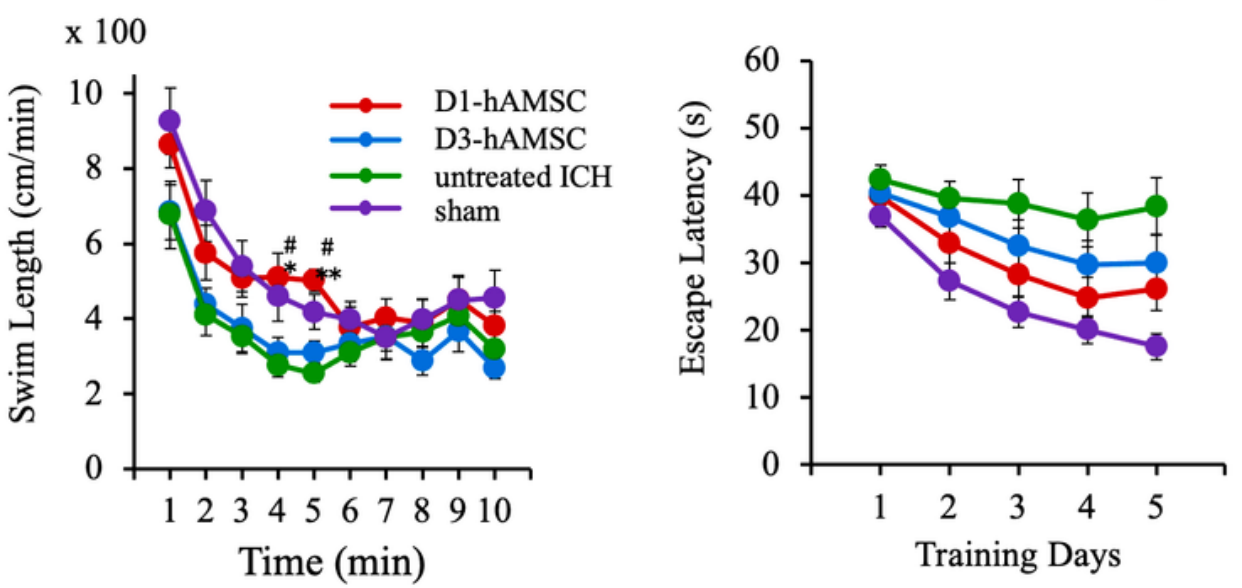

D. Passive Avoidance Learning

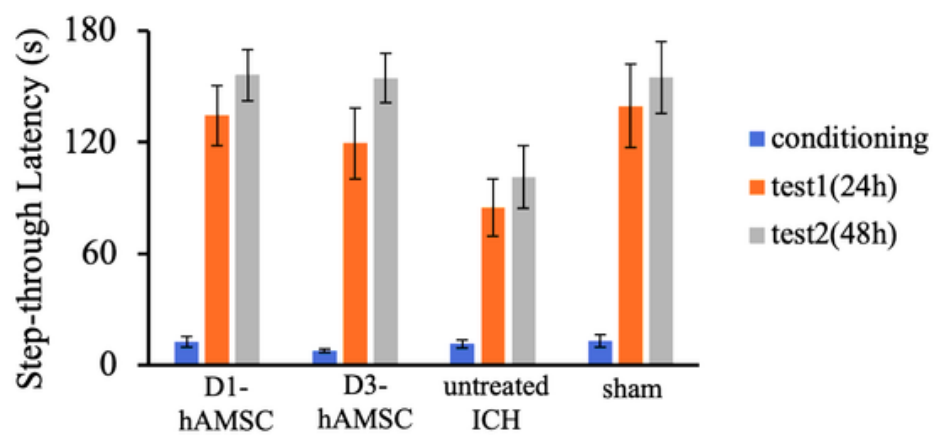

Figure 2

Early intravenous administration of hAMSCs might improve ICH-induced neurobehavioral deficits during the subacute phase. A. a protocol of neurobehavioral tests to optimize the timing of the hAMSC 
administration. The ICH-bearing mice were divided into four groups: D1-hAMSC group ( $n=12)$, D3-hAMSC groups $(n=12)$, untreated ICH group ( $n=11)$, and sham group $(n=12)$. The mice were then subject to the following neurobehavioral tests at Day 29 and later: open space swimming test (B), water maze learning test (C), and passive avoidance learning test (D). Data are plotted in mean \pm SEM. $P$ values are based on Tukey-Kramer test. * $\mathrm{P}<.05$ and $* * \mathrm{P}<.01$ compared with the ICH group. \# $\mathrm{P}<.05$ and \#\# $\mathrm{P}<.01$ compared with the D3-hAMSC group.
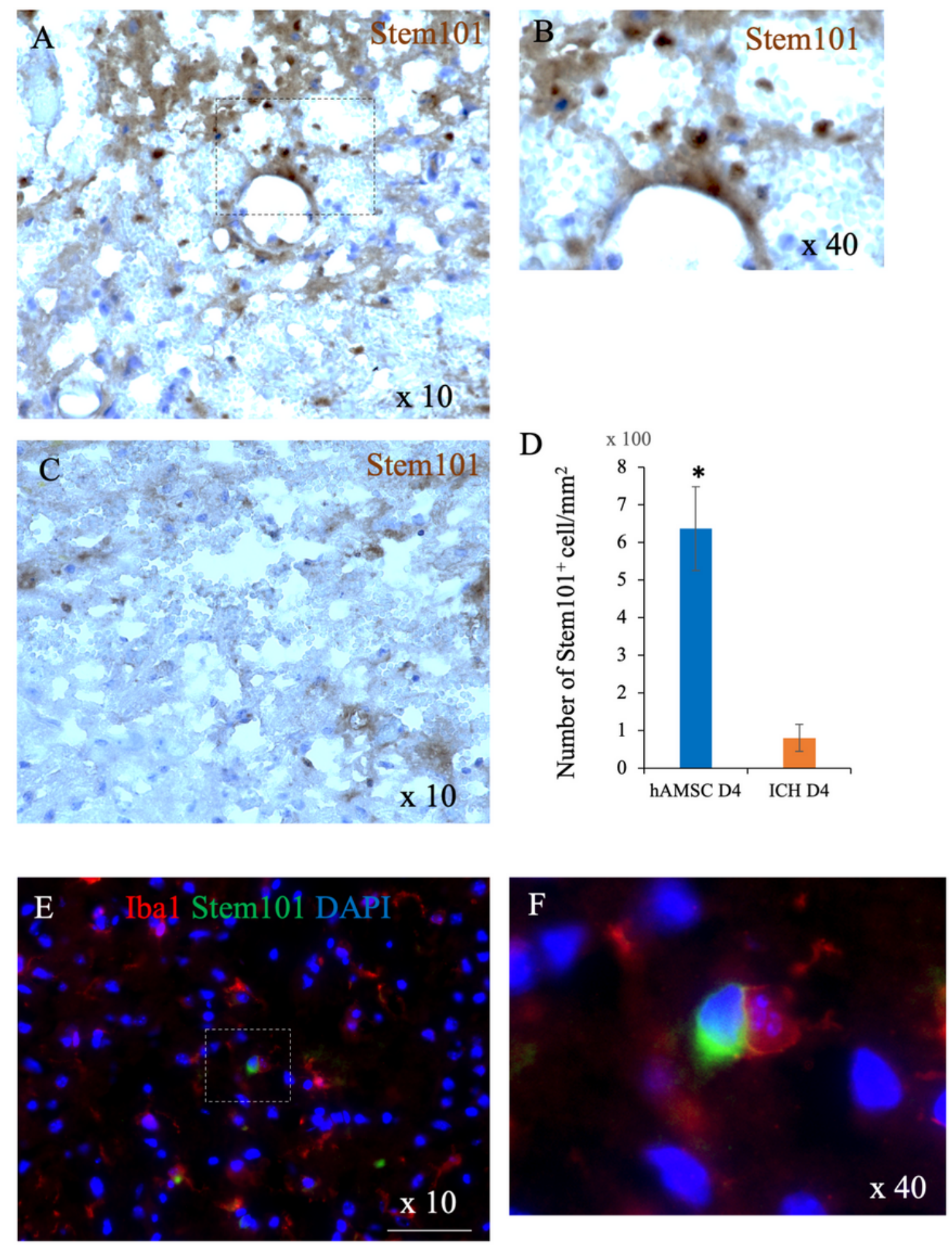

Figure 3 
A small number of hAMSCs pass through the blood-brain barrier and interact with macrophage or microglial cell. Representative images of Stem101 staining of the ICH lesions at Day 4. A, the hAMSC group, magnification: $x 10$. B, the hAMSC group, magnification: x40. C, the ICH group, magnification: $x 10$. $\mathrm{D}$, the number of STEM101-reactive cells around the ICH lesions were enumerated. Double staining of Stem101 and Iba1 in the ICH lesion in the hAMSC group (E.F). Scale bars indicate $100 \mathrm{um.}$
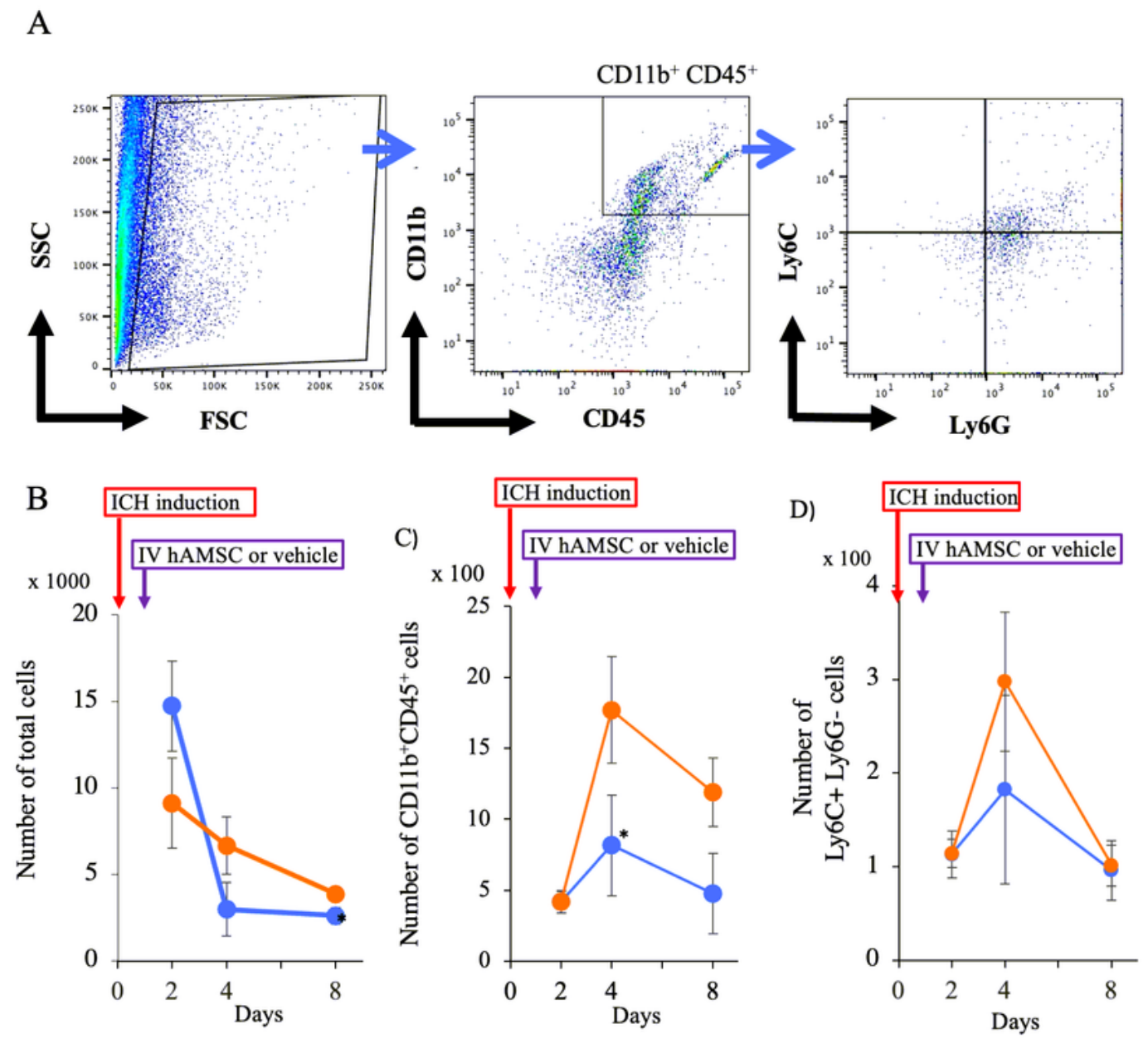

E)

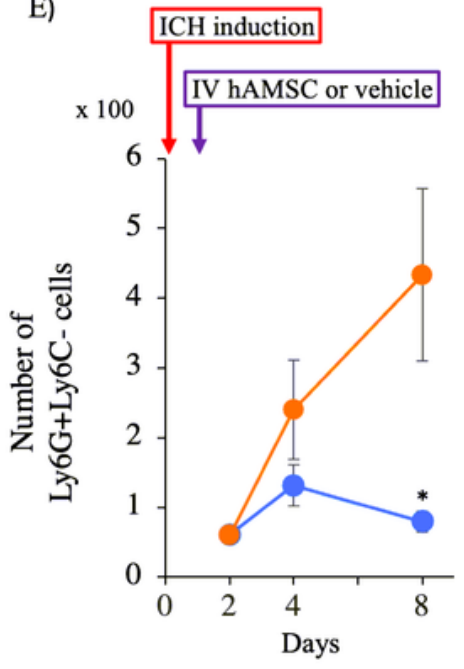

Figure 4 
A hAMSC administration decreases the number of CD11b+CD45+ cells, Ly6C+ and Ly6G+ cells in the ICH lesions. A Representative gating strategy of the flow cytometry for CD11b CD45 Ly6C Ly6G cells. Data were obtained from the ICH lesions at Days 2, 4 and, 8 . B, the total cell number. $\mathrm{C}$, the number of CD11b+CD45+ cells. D, the number of CD11b+CD45+Ly6C+Ly6G- cells. E, the number of $\mathrm{CD} 11 \mathrm{~b}+\mathrm{CD} 45+\mathrm{Ly} 6 \mathrm{C}$-Ly6G+ cells. Data are plotted in mean $\pm \mathrm{SEM}$. $P$ values are based on the Wilcoxon test. * $\mathrm{P}<.05$ compared with the ICH group.

A
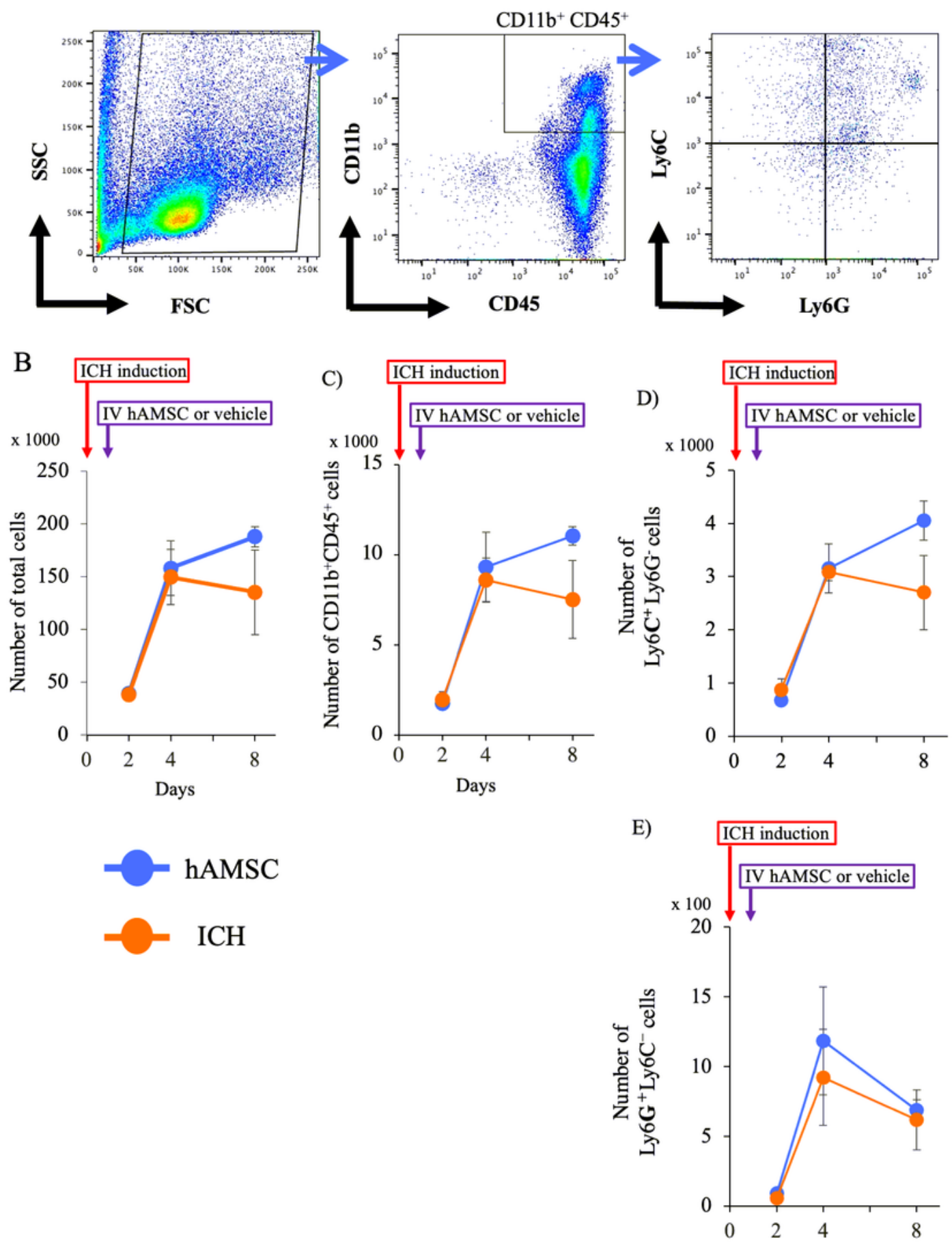

Figure 5 
hAMSC administration does not affect CD11b+CD45+ cells in the spleen. A Representative gating strategy for the flow cytometry of CD11b CD45 Ly6C Ly6G cells. Data were obtained from spleen at Days 2,4 and, 8 . B, the total cell number. $C$, the number of $C D 11 b+C D 45+$ cells. $D$, the number of CD11b+CD45+Ly6C+Ly6G- cells. E, the number of CD11b+CD45+Ly6C-Ly6G+ cells. Data are plotted in mean \pm SEM. $P$ values are based on the Wilcoxon test. * $\mathrm{P}<.05$ compared with the ICH group.
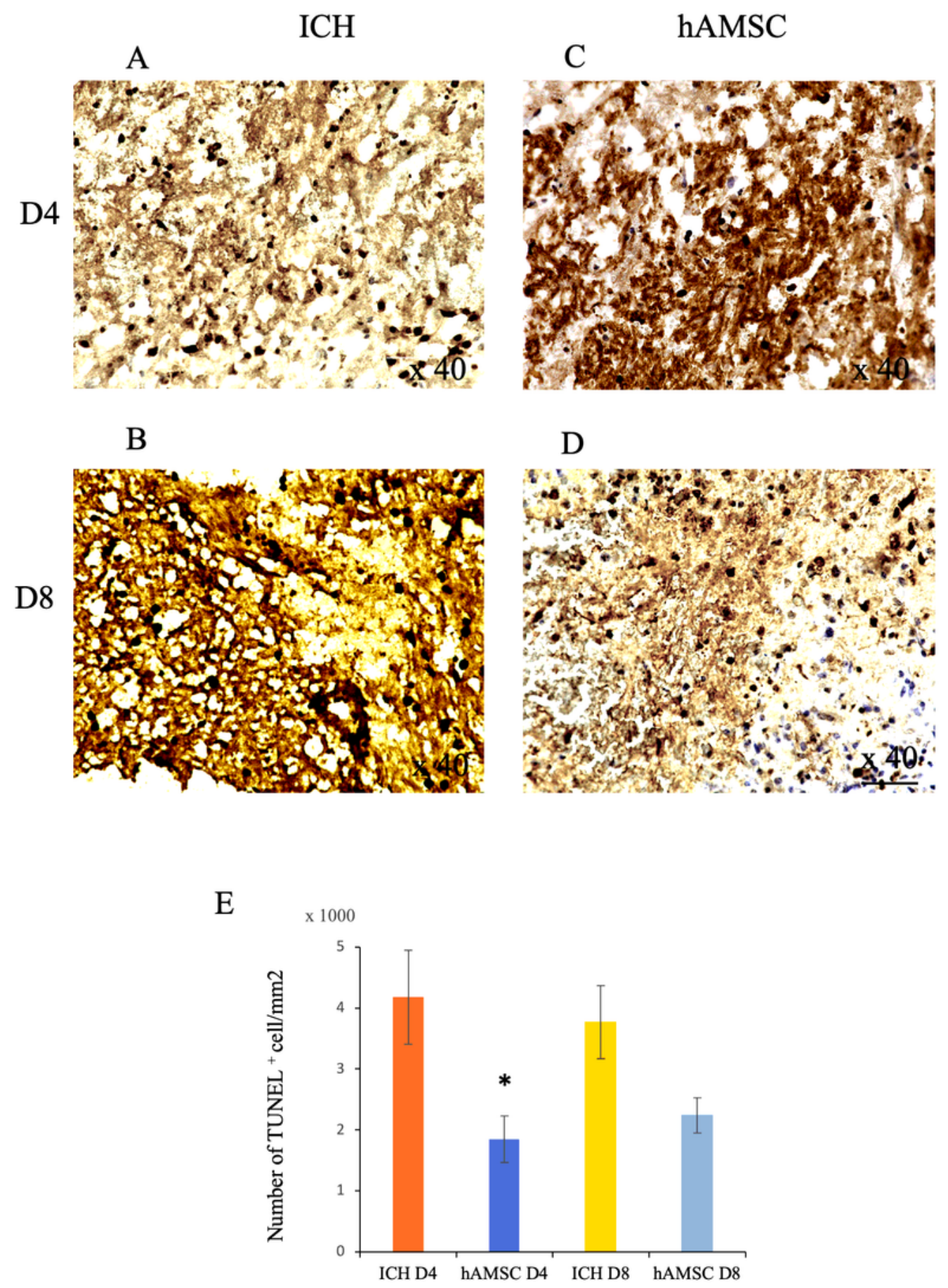

Figure 6 
hAMSCs administration decreases the TUNEL+ cells in the ICH lesions. Representative images of TUNEL staining of the ICH lesions at Days 4 and 8. Magnifications: $x 40$. A, the ICH group at Day 4 . B, the ICH group at Day8. C, the hAMSC group at Day 4. D, the hAMSC group at Day8. E, the numbers of TUNELreactive cells around the $\mathrm{ICH}$ lesions were enumerated. Data are plotted in mean $\pm S E M$. $P$ values are based on Wilcoxon test. * $\mathrm{P}<.05$ compared with the same Day of ICH group. Scale bars indicate $100 \mathrm{um}$.

A)

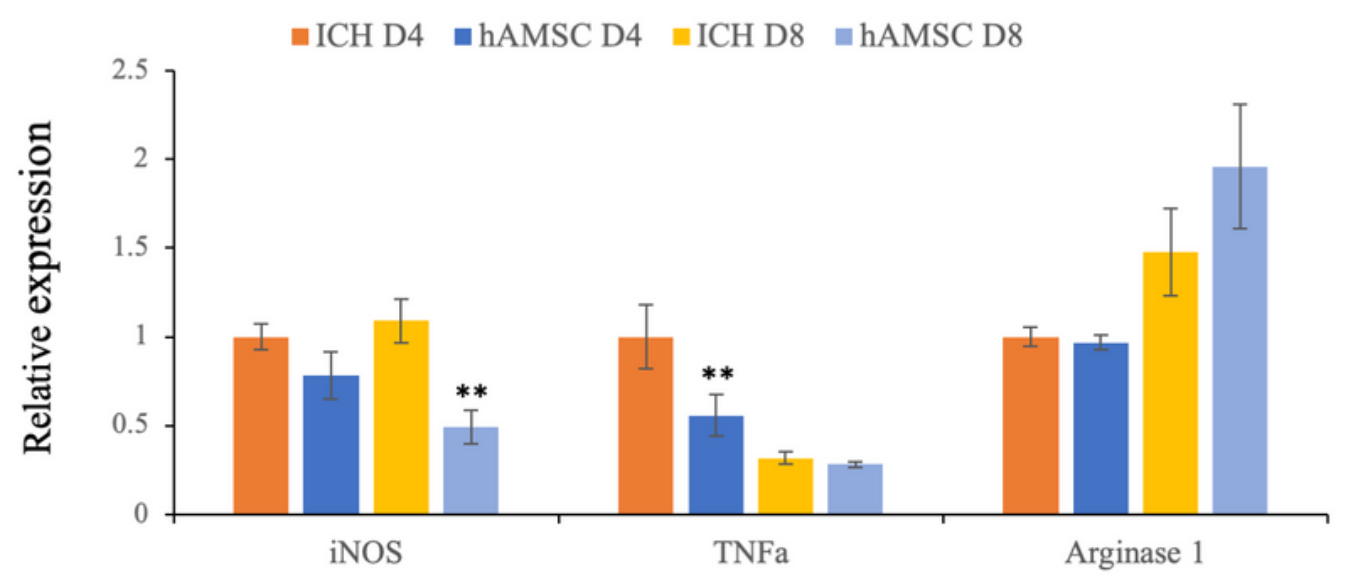

B)

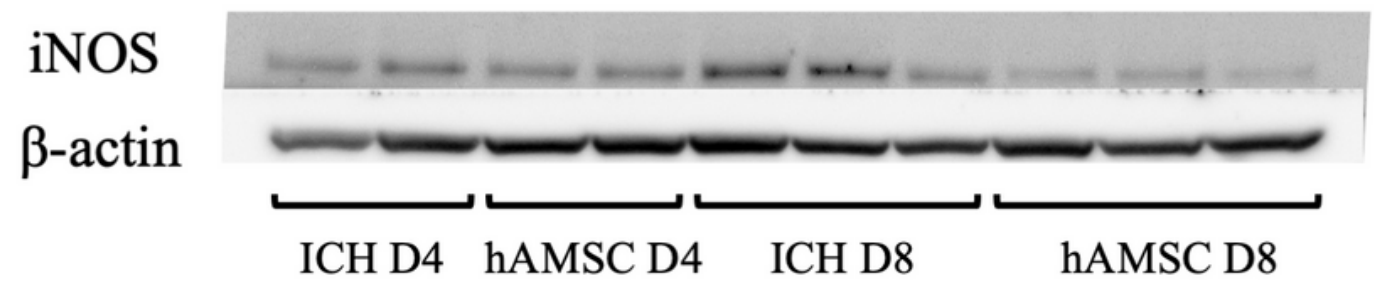

TNF $\alpha$

$\beta$-actin
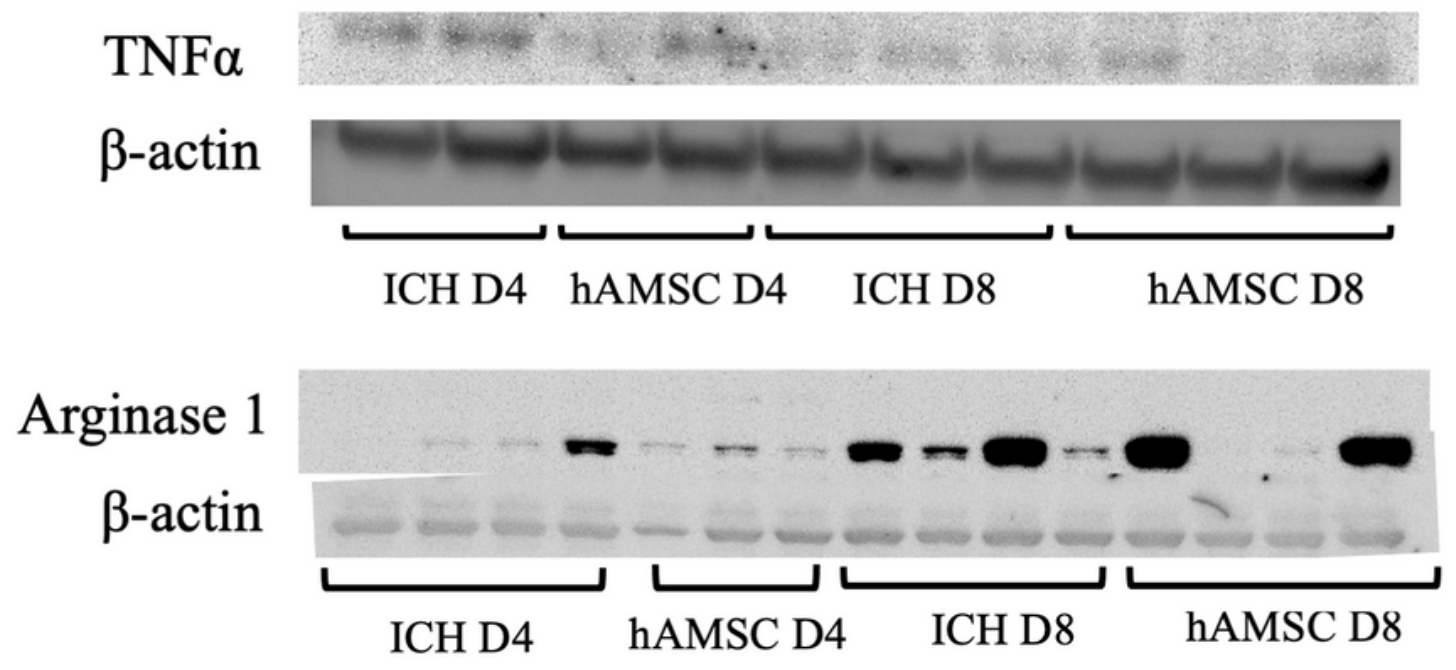

Figure 7 
Intravenous administration of hAMSCs suppress protein expression of iNOS and TNFa. A. The ICH tisses were extracted and subject to Western blotting for macrophage-related factors iNOS, TNFa, and arginage 1. Data were plotted in mean \pm SEM. $P$ values are based on Tukey-Kramer test. ${ }^{*} P<.05$ compared with the $\mathrm{ICH}$ group at the same day. B. Representive image of protein levels of iNOS, TNFa, and arginase 1.

\section{Supplementary Files}

This is a list of supplementary files associated with this preprint. Click to download.

- Sup1.tiff 